\title{
Evde Bakım Hastalarında Görülen Yeni Ürolojik Problemler: Çıkmayan Sondalar
}

\section{New Urologic Problems in Home Care Patients: Adhesive Cathater}

\author{
iD Yasemin Korkut ${ }^{1}$, iD Bekir Aras ${ }^{2}$, iD Efkan Kenan ${ }^{1}$ \\ ${ }^{1}$ Kütahya Sağlık Bilimleri Üniversitesi Tıp Fakültesi Aile Hekimliği AD \\ ${ }^{2}$ Kütahya Sağlık Bilimleri Üniversitesi Tıp Fakültesi Üroloji AD
}

\section{$\ddot{O} z$}

Amaç: Evde sağlık hizmeti alan hastalardaki ürolojik problemlerin ve çözüm önerilerinin değerlendirilmesi amaçlanmıştır.

Gereç ve Yöntem: Calıșmaya, Ocak 2017- Subat 2019 yılları arasında evde sağlık hizmeti alan ve her ay düzenli takibi yapılan 1950 hasta içerisinden kronik üretral kateter kullanımı olan 99 hasta alındı. Hastaların ve sağlık personelinin karşılaşı̆ı̆ı problemler, bu problemler ile baş edilme yöntemleri ve üroloji uzmanına başvuru nedenleri kaydedildi.

\begin{abstract}
Bulgular: Çalışmaya alınan hastaların ortalama yaşları 77,3 (48-96) idi. Hastaların 55'i (\%55,5) erkek idi. Evde bakım hastalarının birincil hastalıkları arasında en çok görülen $58(\% 58,5)$ ile nörolojik sorunlardı. Karşılaşılan ürolojik sorunlar ise sırası ile $\% 18,1$ hastada üriner enfeksiyon, \%18,1 hastada sondanın çıkmaması, \%15,1 hastada kronik irritasyona bağlı üretral erozyon ve \%8 hastada hematüri görüldü. Üriner enfeksiyonu olan hastalara antibiyoterapi uygulandı. Hematüri, irrigasyon yapılarak ve antikoagülan kullanımı kesilebiliyorsa ara verilerek yerinde tedavi edildi. Üretromeatal erozyonu olan hastalarda prezervatif sondaya geçildi yada temiz aralıklı kateterizasyon yapılıp lokal pomad kullanılarak tedavi edildi. Sondası çıkartılamayan hastalar üroloji uzmanına danışılmak üzere hastaneye getirildi ve sonda girişimsel işlemler uygulanarak (üretral veya suprapubik) çıkarıldı.
\end{abstract}

Sonuç: Evde bakım hastalarının karșılaștığı sorunlar içerisinde ürolojik problemler \% 60 oranında görülmekte olup, bu problemlerin düșük bir oranı üroloji uzman desteği gerektirmektedir.

Anahtar Sözcükler: üretral katater, üroloji, evde sağllk

\begin{abstract}
Objective: The aim of this study was to evaluate urological problems and solutions in patients receiving home health care.
\end{abstract}

Material and Method: The study included 99 patients were with chronic urethral catheter use among 1950 patients who received home health care between January 2017 and February 2019. The problems faced by patients and health personnel, ways to deal with problems and the reasons for applying to urology specialist were recorded.

Results: The mean age of the patients included in the study was 77.3 (48-96) years. Fifty-five patients (55.5\%) were male. Among the primary diseases of home care patients, $58(58.5 \%)$ were the most common neurological problems. The urological problems were urinary infection in $18.1 \%$, inability to remove the catheter in $18.1 \%$, urethral erosion due to chronic irritation in $15.1 \%$ and hematuria in $8 \%$. Antibiotherapy was applied to patients with urinary infection. Hematuria was treated in situ by irrigation and interruption if anticoagulant use was discontinued. In patients with urethromeatal erosion, a condom catheter was passed or a clean intermittent catheterization was performed and treated using local ointment. The patients who could not be probed were brought to the hospital for consultation with the urologist and the catheter was removed by interventional procedures (urethral or suprapubic).

Conclusion: Urological problems are seen in $60 \%$ of the problems faced by home care patients, and a low percentage of these problems require urologist support.

Keywords: urethral catheter, urology, home care

Yazışma Adresi: Yasemin Korkut, Kütahya Sağlık Bilimleri Üniversitesi Tıp Fakültesi Aile Hekimliği AD

E-Posta: ykorkut95@yahoo.com

Alınma Tarihi: 18.12.2019 / Kabul Tarihi: 14.07.2020 / Yayımlanma Tarihi: 15.06.2021

Evde Bakım Hastalarında Ürolojik Problemler - Korkut ve ark. 
Uzun süreli kalıcı üretral kateterler idrar kaçırma veya idrar retansiyonu olan kişilerin bakımında sık kullanılan materyallerdendir. Bu kalıcı kateterler genellikle evde, hastanede ve özel sağlık bakımı ortamlarında idrar yolu sorunları olan insanlarda kullanılır. Uzun süreli kateter kullanımıyla ilişkili birçok potansiyel komplikasyon ve yan etki görülmektedir ve kateter kullanımının yaygınlığı ülkeler ve sağlık bakımı ortamları arasında değişmektedir (1).

Sørbye ve ark. tarafindan yapılan bir araştırma, İtalya'da erkeklerin\% 35,9'unun ve kadın yaşlı evde bakım müşterilerinin \% 27,4'ünün kalıcı, aralıklı veya prezervatif kateteri kullandığını tespit ederken, bu kateterlerin kullanım oranları Finlandiya'da erkeklerde (\% 2,9) ve Çek Cumhuriyeti'nde kadınlarda $(\%, 0,6)$ daha düşük olarak tespit edilmişti (2). Uzun süreli kateter kullanımına bağlı olarak üriner sistem enfeksiyonlar1, mineral birikintilerinden kaynaklanan enkrustasyon ve peri-kateter sızıntısı dahil uzun süreli idrar sondalarının kullanımı ile ilişkili çok iyi bilinen ve yaygın komplikasyonlar ve rahatsızlıklar bilinmektedir.

$\mathrm{Bu}$ çalışmada amaç Kütahya ili evde sağlık birimi tarafından takip edilen daimi üretral kateterli evde bakım hastalarında görülen üretral katetere bağlı komplikasyonları belirlemek ve bu komplikasyonların tedavisinde uygulanan medikal ve cerrahi yöntemleri gözden geçirmektir.

\section{Gereç ve Yöntem}

Çalışmaya Ocak 2017 - Şubat 2019 yılları arasında Kütahya ili evde sağlık birimi tarafından her ay düzenli takibi yapılan ve düzenli kayıtları tutulan 1950 hasta içerisinden daimi üretral kateterli 99 hasta alındı. Kütahya Sağlık Bilimleri Yerel Etik Kurul'undan etik kurul onay1 14.11.2018 tarihinde 2018/14-13 numaras1 ile alınarak çalışmaya başlandı. Bu hasta grubunda daimi üretral katetere bağlı gelişen komplikasyonlar tespit edilip sınıflandırılarak kayıt altına alındı. Makroskobik hematüri, üriner enfeksiyon, mesane taşı, kateter lümeninin tıkanması, sonda irritasyonuna bağlı penis cildi ve üretral erozyonlar ve çıkarılamayan sondalar olarak tespit edildi. $\mathrm{Bu}$ problemler medikal veya invazif yaklaşımlar ile tedavi edildi.

\section{Bulgular}

Çalışmaya evde bakım hizmeti alan 1950 hastadan üretral foley kateteri olan ve hasta ve hasta yakınlarının uyum sağlayamaması nedeniyle tümü daimi üretral kateter kullanan 55 erkek, 44 kadın olmak üzere toplam 99 hasta alındı. Üretral sondalı olan hastalardan 59 'unda (\% 59,5) daimi sondaya bağlı komplikasyonlar görüldü. 18 $(\% 18,1)$ hastada üriner enfeksiyon, $18(\% 18,1)$ hastada çıarılamayan sonda, $8(\% 8,1)$ hastada hematüri ve 15 hastada $(\% 15,1)$ kronik irritasyona bağlı üretral erozyon tespit edildi (Tablo 1).

Tablo 1. Sondaya bağlı görülen komplikasyonlar

\begin{tabular}{|l|l|l|}
\hline Komplikasyon & $\mathrm{N}=$ say1 & $\%$ \\
\hline Üriner Sistem Enfeksiyonu & 18 & 30,5 \\
\hline Çıkarılamayan Sonda & 18 & 30,5 \\
\hline Hematüri & 8 & 13,6 \\
\hline Üretral Erozyon & 15 & 25,4 \\
\hline
\end{tabular}

Semptomatik üriner enfeksiyonu olan hastaların idrar tahlilleri ile birlikte idrar kültürleri alındı ve kültür sonuçlarına uygun antibiyoterapi ve analjezik ihtiyacı için kreatinin değerine bağlı olarak parasetamol veya nonsteroid antienflamatuar tedavi verildi. Tedavi
Sondaya ilişkili hematürisi olan hastalar için öncelikle üriner us ile hematüri etyolojisi araştırıldı, hematüri sadece sondaya başlı olduğu düşünülüyorsa antikoagülan kullanımına uygun branş konsültasyonlarına danışılarak ara verildi, mesanede organize olmuş hematoma sahip hastalarda ise mesaneye 3 yollu sonda tak1larak 3000 cc izotonik solüsyonu ile $50 \mathrm{cc}$ enjektörler ile mesane irrigasyonu yapılarak hematom boşaltıldı. Daha sonra 3 yollu sonda ile aynı gün sonda rengi açık kalacak şekilde en az 24 saat hematüri açılana kadar mesanenin izotonik ile serum seti ile ayarlanarak irrigasyona devam edildi. Hematürinin bittiği kanaatine varılınca irrigasyon kesildi.

Resim 1: Transrektal US eşliğinde balonun iğne ile patlatılması

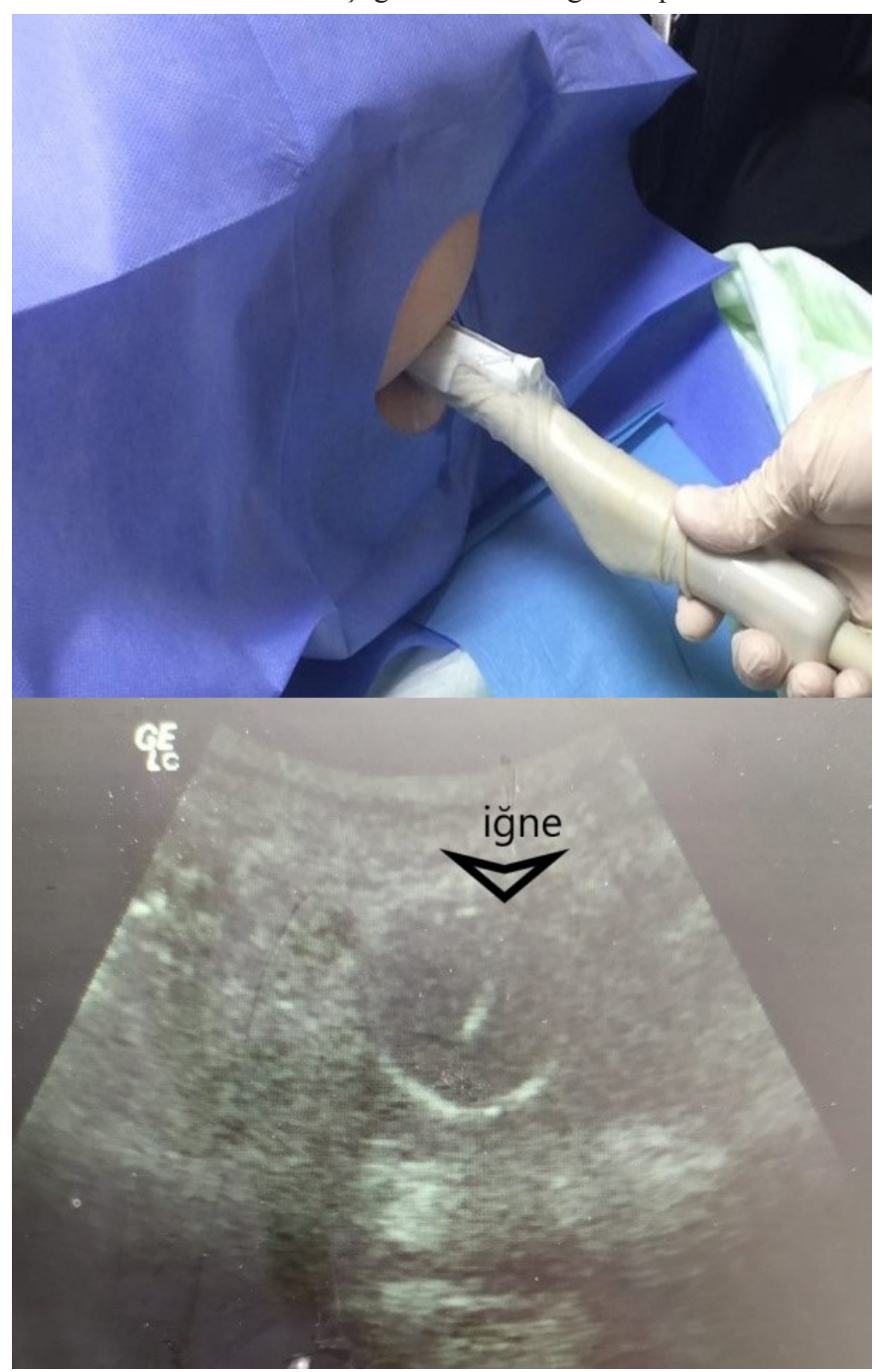

Sondaya bağlı olarak gelişen üretromeatal erozyonları olan hastaların sondaları alınarak perkütan suprapubik sistostomi veya temiz aralıklı kateterizasyona geçildi ve erode olan alan lokal epitelizan pomad kullanılarak konservatif olarak tedavi edildi.

Üretral kateteri çıkarılamayan hastaların tanımında sonda balonunun boşaltılamaması ve vücut dışına çıkarılamaması durumu olarak tanımlandı. İlk olarak foley kateter vucut dışında kalan Y kısmından kesilerek balon içeriğinin boşalması beklendi. Balonu boşalmayan sondalarda ikinci olarak üreteral stent klavuz teli ile sonda içerisinde oluşan enkrustasyonlar açılmaya çalışıldı. Üçüncü yol olarak cinsiyete göre tedavi edildi. 13 erkek hastada sonda balonu $30 \mathrm{cc}$ kadar şişirilerek lokal anestezi altında suprapubik ultrason kılavuzluğunda ile spinal iğne ile patlatıldı. Obezite nedeniyele 3 hastada lokal 
anestezi ile transrektal ultrason eşliğinde prostat biyopsi iğnesi ile balon patlatıldı (Resim 1). İki kadın hastada ise sonda mesane boynuna doğru traksiyon ile çekilerek üretradan balon görülmesi sağlanıp 22 gauge branül ile balonun patlatılması sağlandı. Tüm hastalardan sondalar tarif edilen şekillerde çıkarıldı. Çıkarılamayan sondaların tamamı latex ürünü olan sondalar olup hastalar sonda yapıları hakkında bilgilendirildi ve silikon kateterlere geçişi sağlandı.

\section{Tartışma}

Ürolojik veya diğer sistemik nedenlerle daimi üretral kateterle takip edilen hastalarda katetere bağlı komplikasyonlar sıklıkla görülmektedir $(1,2)$. Literatürde Saint ve ark.'larının çalışmasında enfeksiyon dışı komplikasyonlar enfeksiyöz komplikasyonlardan 5 kat daha yüksek oranda görüldüğü belirtilmiştir (1). En s1k lokal ağrı ve rahatsızlık hissi görülmektedir. Silikon sondaların üriner enfeksiyon ve diğer komplikasyonları azalttığı yapılan çalışmalarda gösterilse de kesin bir çözüm sunulamamıştır (3).

Günümüzde kullanılan idrar sondalarının büyük çoğunluğu, doğal kauçuk (latex) veya polisopren adlı maddeden imal edilmektedir. Doğal lateks düşük maliyetli olmasının yanında kolay ve kısa sürede şekillendirilebilmesi, işlenebilmesi nedeniyle aynı zamanda üretim maliyetlerini de azalttığından kateter üretiminde halen sıklıkla kullanılmaktadır. Aynı zamanda doğal kauçuğun, yoğunluk, sertlik, uzama katsayısı, gerilme kuvveti gibi fiziksel özelliklerinden kaynaklanan avantajları bu hammaddenin yerine koyulabilecek alternatiflerini sınırlamaktadır. Ancak kauçuk yapıda malzemelerin neden olduğu zayıf biyo-uyumluluk, yüksek idrar yolu enfeksiyonu yatkınlığı ve lümen tıkanması sıklığında artış gibi sorunlar, sağlık çalışanları tarafından fark edilmiş ve bildirilmiştir (4). Bunun dışında insan immun sisteminin, kauçuk içeriğinde bulunan proteinler ile aktivasyonu sonucu gelişen ve lateks alerjisi olarak tanımlanan bir tablo da ortaya konmuştur (5). Tüm bu sorunlar, sonda üreticilerinin yeni çözümler aramasına neden olmuş ve günümüzde gümüş, hidrojel, politetrafloroetilen veya silikon kaplanmış kauçuk sondaların ya da tamamen silikon hammaddesinin kullanıldı̆̆ 1 sondaların üretimi ile sonuçlanmıştır. Kauçuğun polimerik kaplama ile muamele edilmesi sonucunda biyo-uyumluluğunun iyileştiği, nispeten yüzey kayganlığının artması nedeniyle uygulanmasının kolaylaştığı, uygun esneklik ve sertlik değerlerine ulaşılabildiği iddia edilmektedir (4). Saf silikon sondalar ise fiziksel, kimyasal ve biyouyumluluk özellikleri yönünden, üriner kateterizasyon ile ilgili olduğu bildirilen birçok sorun için çözüm olarak görülmekle birlikte üretim maliyetleri diğer sonda tiplerine oranla yüksektir. Bunlara ek olarak Kowalczuk ve ark.'nın yaptığı çalışmada sondaların çeşitli antibiyotikler ile muamele edilmesi ile hem mikroorganizmaların yapışmasının engellendiği hem de sitotoksik etkilerinin azaltıldığı gösterilmiştir (6).

Literatürde yapılan çalışmalarda çıkarılamayan sondaların farklı teknikler ile çıkarılabileceği anlatılmıştır (7-9). Daneshmand ve ark. öncelikle sonda distalinin kesilip sonda balonunun kendiliğinden boşalabileceği önerilmektedir. $\mathrm{Bu}$ yöntemin başarısızlığında üreteral stent klavuz teli ile balon kanalının açılması önerilmektedir. $\mathrm{Bu}$ yöntemin de balonun proksimal kesiminde tıkanıklık olmas durumunda başarı şansı düşktür. Son olarak lokal anestezi sonrası spinal iğne ile ultrason eşliğinde sonda balonunun patlatılması önerilmiştir. Biz de çalışmamızda sırasıyla bu yöntemleri uyguladık. Suprapubik yolla obezite nedeniyle zorlandığımız hastalarda transrektal yolu kullandık. Kadınlarda ise sondayı mesane boynuna çekerek 22 gauge branül ile sonda balonunu patlatma yöntemini kullandik.
Özetle çeşitli nedenlerle daimi üretral kateter ile takip edilen hastaların sondaya bağlı komplikasyon gelişme riski oldukça yüksek orandadır. $\mathrm{Bu}$ komplikasyonların yönetiminde hastaların genel durumu ve komorbiditeleri nedeniyle zorluklar yaşanmaktadır. Biz de çalışmamızda bu komplikasyonlardan nadir görülen ancak yönetimi zor olan çıkmayan sondaların literatürde de tariflenen yöntemler ile çıkarılabileceğini gösterdik.

Sonuç: Gelişen tedavi yöntemleri ve buna ulaşımın kolay olması ile birlikte artan insan ömrü ile birlikte evde bakıma ihtiyaç duyulan hasta sayısında belirgin olarak bir artış görülmektedir. Buna balı olarak evde bakım hastalarının karşılaştığı sorunlar içerisinde ürolojik problemler \% 60 gibi yüksek bir oranda görülmektedir. Bu problemlerin düşük bir oranı üroloji uzman desteği gerektirmektedir.

\section{Kaynaklar}

1. Stensballe J, Looms D, Nielsen PN, Tvede M. Hydrophilic-coated catheters for intermittent catheterisation reduce urethral micro trauma: a prospective, randomised, participant-blinded, crossover study of three different types of catheters. Eur Urol 2005;48(6):978-83.

2. Sørbye LW, Finne-Soveri H, Ljunggren G, Topinkova E, Garms-Homolova V, Jensdóttir AB; AdHOC Project Research Group. Urinary incontinence and use of pads-clinical features and need for help in home care at 11 sites in Europe. Scand J Caring Sci 2009;23(1):33-44.

3. Saint S, Trautner BW, Fowler KE, Colozzi J, Ratz D. A Multicenter Study of Patient-Reported Infectious and Noninfectious Complications Associated With Indwelling Urethral Catheters. JAMA Intern Med 2018;178(8):1078-85.

4. Feneley RC, Kunin CM, Stickler DJ. An indwelling urinary catheter for the 21st century BJU Int 2012;109(12):1746-9.

5. Lawrence EL, Turner IG. Materials for urinary catheters: a review of their history and development in the UK. Med Eng Phys 2005; 27(6): 443-53.

6. Hunt LW, Kelkar P, Reed CE, Yunginger JW. Management of occupational allergy to natural rubber latex in a medical center: the importance of quantitative latex allergen measurement and objective follow-up. J Allergy Clin Immunol 2002; 110(2): 96-106.

7. Kowalczuk D, Ginalska G, Przekora A. The cytotoxicity assessment of the novel latex urinary catheter with prolonged antimicrobial activity. J Biomed Mater Res A 2019;8(2): $222-8$

8.Gonzalgo ML, Walsh PC. Balloon cuffing and management of the entrapped Foley catheter. Urology 2003;61(4):825-7.

9. Daneshmand S1, Youssefzadeh D, Skinner EC. Review of techniques to remove a Foley catheter when the balloon does not deflate. Urology 2002;59(1):127-9.

10. Gulmez I, Ekmekcioglu O, Karacagil M: A comparison of various methods to burst Foley catheter balloons and the risk of free-fragment formation. Br J Urol 1996; 77: 716-8.

11. Rees $M$, and Joseph AEA: Ultrasound guided suprapubic puncture - a new simple way of releasing a blocked Foley balloon. Br J Urol 1981;53: 196. 